Purdue University Purdue e-Pubs

\title{
Toward a Unified Theory of Business Information
}

Hal P. Kirkwood Jr

Purdue University - Main Campus, kirkwood@purdue.edu

Follow this and additional works at: http://docs.lib.purdue.edu/lib_fsdocs

Part of the Business Administration, Management, and Operations Commons, Business Intelligence Commons, and the Information Literacy Commons

\section{Recommended Citation}

Kirkwood, Hal P. Toward a unified theory of business information. Business Information Review. Vol 34, Issue 3, pp. 143 - 149

First published date: August-23-2017

$10.1177 / 0266382117722442$ 


\title{
Toward a unified theory of business information
}

Business Information Review

$1-7$

(C) The Author(s) 2017

Reprints and permission:

sagepub.co.uk/journalsPermissions.nav DOI: | 0.1 I77/0266382 I I 7722442

journals.sagepub.com/home/bir

(S)AGE

\author{
Hal P Kirkwood \\ Purdue University, USA
}

\begin{abstract}
This article analyses and discusses concepts of business information, with a view to developing a unified theory of business information to help underpin professional information work.
\end{abstract}

\author{
Keywords \\ Business Information, Information Literacy, Concept Mapping
}

\section{Introduction}

Business information consists of a multifaceted array of topics and subtopics interconnected to form the overall business information environment. Business information literacy, as defined here, is the comprehension of the varied topics and subtopics of business along with the ability to search and use business-focused information resources to make informed financially motivated decisions. While information literacy generally remains a concept relevant to academic librarians, business information literacy does bridge the apparent gap between academic librarians and corporate librarians; business information literacy can be translated to competitive intelligence in more applied business settings. The importance of understanding the business environment cannot be overstated in the current hypercompetitive markets. Effective decision-making relies on the efficient and timely use of quality information. Understanding the connections and flow of business information is beneficial for this improved decisionmaking perspective.

Over the past 30 years, there have been a variety of studies into business information literacy. The definition of business information literacy itself is inconsistent as researched by Avtar Natt (2013). Additionally, there have been numerous attempts at creating relevant analysis models, competency skill lists, and frameworks for information literacy, or more specifically business information literacy. Within the realm of business strategy, there exist dozens of techniques for conducting effective decision-making by framing the business environment a specific way.

In spite of all of this, there is no straightforward attempt at a business information framework to set the context for decision-making techniques. This article proposes to accomplish this endeavor by describing and diagramming the underlying concepts of business information whereby resources and databases could be matched against it; whereby business information literacy instruction could begin, regardless of any specific resource so that the determination of what sources to use will be more apparent.

\section{Literature review}

An early attempt to model the flow of information was Krishna Subramanyam's model of the evolution of scientific information designed (Subramanyam, 1981) and then subsequently revisited by Curl (2001). The original model showed the changing type of information while an inner circle tracked the passage of time. Curl proceeded to create a revised version focusing on the information life cycle for improved information literacy instruction. The purpose of this revised model was to create a relevant framework more appropriate for undergraduate instruction. Cunningham (2003) published a set of competency skills for business students that were tied to the Association of College and Research Libraries (ACRL) information competency standards. She ported the ACRL standards into a business information literacy framework. Business information-specific standards and outcomes were developed creating a functional list of competencies for potential student assessment. There are additional endeavors related to the ACRL standards currently underway but not yet published. Prof. Tegarden

\section{Corresponding author:}

Hal P Kirkwood.

Email: kirkwood@purdue.edu 
(1999) wrote a tutorial paper on business information visualization that focused on a variety of aspects and tools for visualizing facets of business information for its use in business problem-solving tasks. The article explains the purpose and potential of visualization of business data while providing concrete examples. It does not, however, create a visualization of the overarching business information environment. Spencer (2009) in conjunction with Jisc and the British Library conducted a study on the British business information environment titled Business Information Resources: Landscape and Feasibility Study which analyzed information providers, information customers, and the future of business information provision. The major categories considered were market information, company financial information, product and supplier information, mailing lists, intellectual property, statistics and economic news, and trade and business news. Again, no visualization of the business information environment was provided.

The 2002 book The Basic Business Library, edited by Rashelle Karp, focused on a topical consideration of business information with chapters on key source groups and business library services (Karp, 2002). Lucy Heckman's How to Find Business Information is similar to Karp's volume, providing a mix of key resources with descriptions and short summaries on key business information topics, such as: how to find industry information, the stock market, information about companies, investing, insurance, and several others (Heckman, 2011). While these both provide useful information on seeking business information, neither creates a model for understanding the flow of business information. Gil and Reyes (2012), in International Business Research: Strategies and Resources, present an interesting introduction describing the connection between trade, globalization, and international business. Gil and Reyes then look at the overall process with chapters focusing on basic tools and sources, the role of money and financial markets, major organizations and information providers, regional economic organizations and trading blocs, strategies for conducting international company research, classification systems, market research, and international investments. Each chapter is liberally filled with relevant resources and databases.

Strauss's Handbook of Business Information, rewritten and updated by Rita Moss, similarly focuses on providing a plethora of resources grouped by topic and by type with brief summaries of each element, along with descriptions of each resource (Moss, 2004). The strength of the Strauss Handbook is in the very detailed categories and subcategories of resources showing the full scope of business information. Eileen Abels' and Deborah Klein's Business Information: Needs and Strategies provide the deepest explanation of business information covering how it is generated, who generates it, the influence of geography on it, as well as analysis of business users and their needs (Abels and Klein, 2008). Similar to the Strauss Handbook, Abels and Klein provide concise descriptions of the wide variety of types of documents and sources. A particularly interesting portion of Abels' book is the section on 'Putting Business Information to Work' which provides a selection of information-seeking scenarios. This section provides more substantial examples of how to effectively use information in business and thus puts the earlier definitions and explanations into a decision-making context.

\section{Models and methods}

Effective business analysis relies on the use of methods and models for specific facets of business. Well-known models such as strengths, weaknesses, opportunities, threats or political, environmental, social, technological pose specific information gathering categories to fill in to utilize the model. While others, like Porter's 5 forces or value chain analysis, set a framework to work within for improved decision-making; the former looking at the influences within an industry and the latter looking at the steps toward your customers. Thus, the seeking of business information is in large part driven by the analysis technique chosen by the searcher.

Christy Donaldson specifically tied the concept of information literacy to a problem-solving model developed by McKinsey \& Company (Donaldson, 2004). She adapted this model to teach graduate business students to effectively determine their information need, analyze the information they acquire, and then present it effectively. Estelle Mayer collected a list of approximately 50 different competitive intelligence analysis techniques all categorized into smaller groups: industry structure and competitiveness, future market size estimation and analysis, customer intelligence, growth path analysis, financial analysis, competitor's management team profiling, future trends analysis, competitive strategy exploration, and predicting competitors' future strategy (Mayer, 2013). Fleisher and Bensoussan's (2007) book Business and Competitive Analysis details almost two dozen analysis techniques. The book also explains a format for evaluating analysis methods within a framework. Michael Porter of Harvard University has developed some of the most famous models for analyzing business situations. These models include the Porter's Generic Strategies, Porter's Diamond of National Advantage, and the most well-known Porter's Five Forces (Porter, 1985, 1991). It is exactly these types of methods that are so powerful within business analysis for understanding how to analyze a business situation in a particular way.

The significant commonality with the models and intelligence techniques is that they do not stand on their 
own for improved decision-making. The techniques are simply frameworks to be used in specific analytic situations that must be supplied with concrete business information or they serve no actual purpose. Models provide a framework to analyze a situation and to build information into so that you can gain perspective and knowledge. Once there you can then proceed to make informed business decisions.

\section{Developing a business information model}

It is this concept of business analysis models that has led to the idea of a 'unified theory' of business information. Unified theory, unified field theory, or the "Theory of Everything' is well known in science as a 'means of tying together all known phenomena to explain the nature and behavior of all matter and energy in existence' (Rouse, 2005). Thus, a unified theory of business information proposes to focus on viewing business information within the context of a connected and purposeful visualization.

Business information is categorized into specific topics: company information, industry or market information, business publications, country economic data, accounting, and others. The topics are frequently dealt with individually by looking at the information available in the sources and databases that cover that topic. A cursory search of the database Library, Information Science and Technology Abstracts produces a list of over 70 articles focused on company research and over 100 articles focused on market research.

Information flows from one area to another and causes business entities to react, creating new information and forcing new decisions. As mentioned earlier, there are numerous guides and directories that provide lists of the resources within each category. This does not, however, explain what is actually happening with the information as it is generated by the initial sources.

In effect, there is the concept of business information ecosystems. It is this concept which can be unified into a conceptual map of business information. Business information is an area where understanding the ecosystem can be powerful for understanding a business environment. The concept of ecosystems has grown recently in a variety of settings, a recent Deloitte report on business ecosystems stated: driven largely by digital technologies and massively increased connectivity, the economy has been moving beyond narrowly defined industries built around large, vertically integrated, and mainly 'self-contained' corporations. New means of creating value have been developing everywhere in the form of ever-denser and richer networks of connection, collaboration, and interdependence. (Kelly et al., 2015, p. 4)
It is this trend of increasingly interconnected market ecosystems that must be understood for effective strategic decision-making and business success. Understanding how business information is generated within a market ecosystem is the functional component for understanding the broader market ecosystem.

\section{Business information ecosystems Company information}

Companies generate information; this information manifests itself in a variety of locations, sources, and documents. Companies of all types publish press releases, product literature, websites, annual reports, and other sources of public-facing information. These publicfacing sources can contain a wealth of information including but not limited to addresses, executive names and biographies, subsidiaries and divisions, financial data, investment data, supply chain connections, research and development, and short-term and long-term strategic decisions. Publicly traded companies file numerous documents to stock exchange governing bodies which can include 10-K annual and 10-Q quarterly financial filings, 8-K Current Report, S-1 Initial Public Filing, and many others. In the US, public company information is required at the Securities and Exchange Commission in Canada public companies file documents with Canadian Securities Administrators, while in the UK, the collecting body is Companies House. Other countries and their respective stock exchanges have different organizations that require the filing of publicly traded company data and documents. From these collecting sources, it is repackaged into a wide variety of databases and services including Thomson Financial, Mergent, Morningstar, Standard \& Poor's, Lexis-Nexis, Yahoo! Finance, Ran kandFiled.com, and many others.

Private companies do not fall under the same governmental regulations and thus do not supply the same level of information as publicly traded companies. Private companies are not required to provide any publicly available information, except for articles of incorporation documents. What information is available on private companies is gathered from disparate sources. It is also collected in databases by such information providers as PrivCo, Dun \& Bradstreet, Mergent, Lexis-Nexis, ReferenceUSA, among others.

The relevant factor in understanding business information is to understand the motion of this information from the original source, individual companies, into the variety of sources and databases that collect it. Once the information permeates these sources, databases, and individual company websites, it is researched and reacted to the other core business information areas of industries and markets and business articles and journals. 


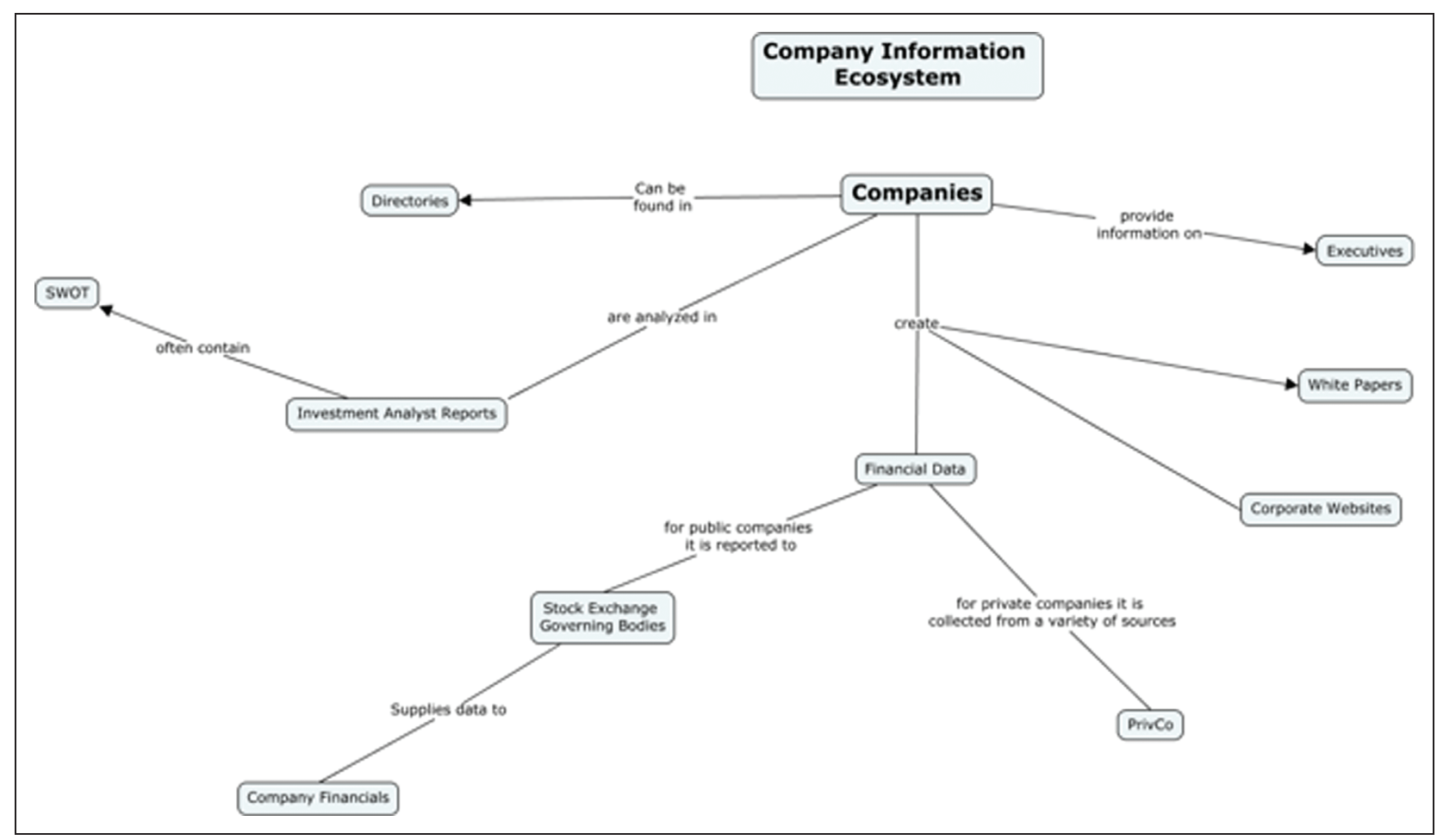

\section{Industries and markets}

Industries and markets are the environment companies live within; the playing field upon which they compete. The information available within this environment consists of documents and sources with a broader view of competing companies' activities. More specifically, industry and market data consist of aggregate statistics merged from individual company reports or from consumer buying data. It also consists of collected statistics from government economic reports, calculated statistics from market research, as well as analysis from industry experts and market researchers. This information is collected within spreadsheets and economic datasets, industry overviews, and market research reports.

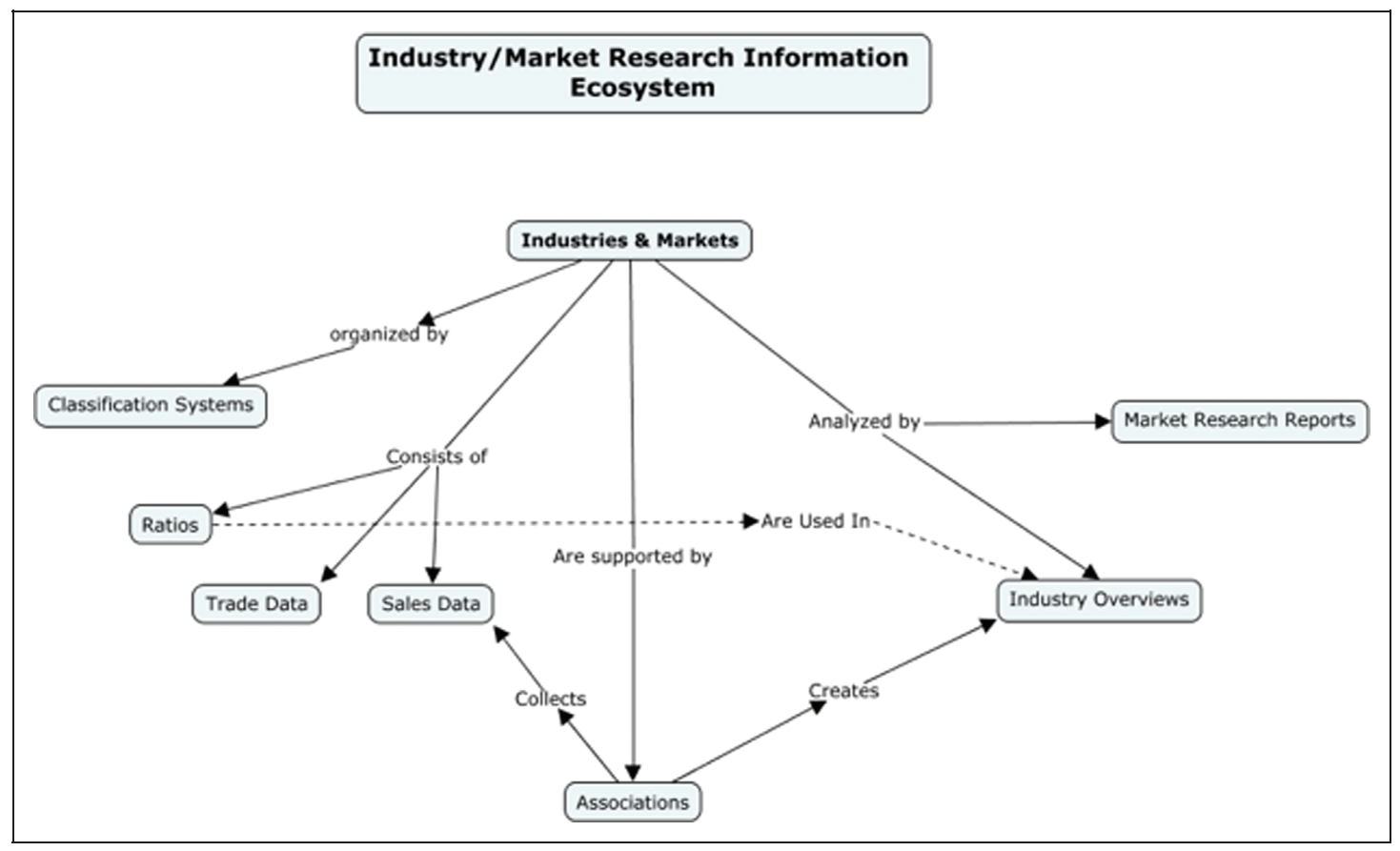


Industry and market-related information is organized using specific classification systems. The numeric data are presented in averages and ratios for analysis and comparison. Key elements of industry and market research include market size, market share, and market segmentation. These three concepts form the primary core to any analysis.

These documents are made available from individual market research publishers or collected in aggregator sites. Numerous databases fit into this category including IBISWorld, Mintel, BCC Research, Plunkett's Research, Frost \& Sullivan, Passport, Standard \& Poor's, MarketResearch. com, and many others. Market research reports provide a greater level of breadth and depth than any other source that is used by marketers, strategists, and executives to determine what direction to proceed in and what decisions should be made to be competitive. Industry overviews look more broadly at a major industry sector, often covering many markets within the overview.

\section{Business articles/journals}

Business articles are a key component of business information research providing access to current information and insight into research. There are a variety of document types within this category: peer-reviewed scholarly articles, trade journals, general business articles, newspapers, and regional (both national and international) publications. These article types all report on company and industry/ market activities from differing perspectives. These perspectives provide a varying degree of depth and interpretation with the business information they contain.

Peer-reviewed scholarly articles frequently provide new data along with prior research and analysis col- lected by the researchers. As its name implies, the article has gone through a peer-review process to vet the content and validity of the research. Peer-reviewed research provides significant depth into a topic; however, it has some limitations including issues of datedness and often a very narrow focus. General business publications that cover major national and international business news focus on not only what happened but the broader ramifications in the marketplace and the world. Trade publications are consistently timelier and contain content that is more applied than peerreviewed research articles; examples include case studies on strategic implementations, product and service reviews, reporting on business activities, and related topics. These articles are all focused on the specific industry covered by the magazine. Almost every industry or market has at least one, if not several, magazines that cover the market and related companies. Similar to trade publications are regional business publications which focus on the impact and actions of markets and companies in proximity to the range of coverage of the magazine. These are useful for identifying smaller scale business actions as well as information on smaller companies.

These types of articles are found within the numerous article databases available from EBSCO, ProQuest, Lexis, Ovid, Emerald, and many others. The research and reporting of business activities creates its own ripple effect within the model as company executives, researchers, and others react to the information within the articles. Competing companies will follow business news events and reported actions closely to determine their own strategic decisions in the future.

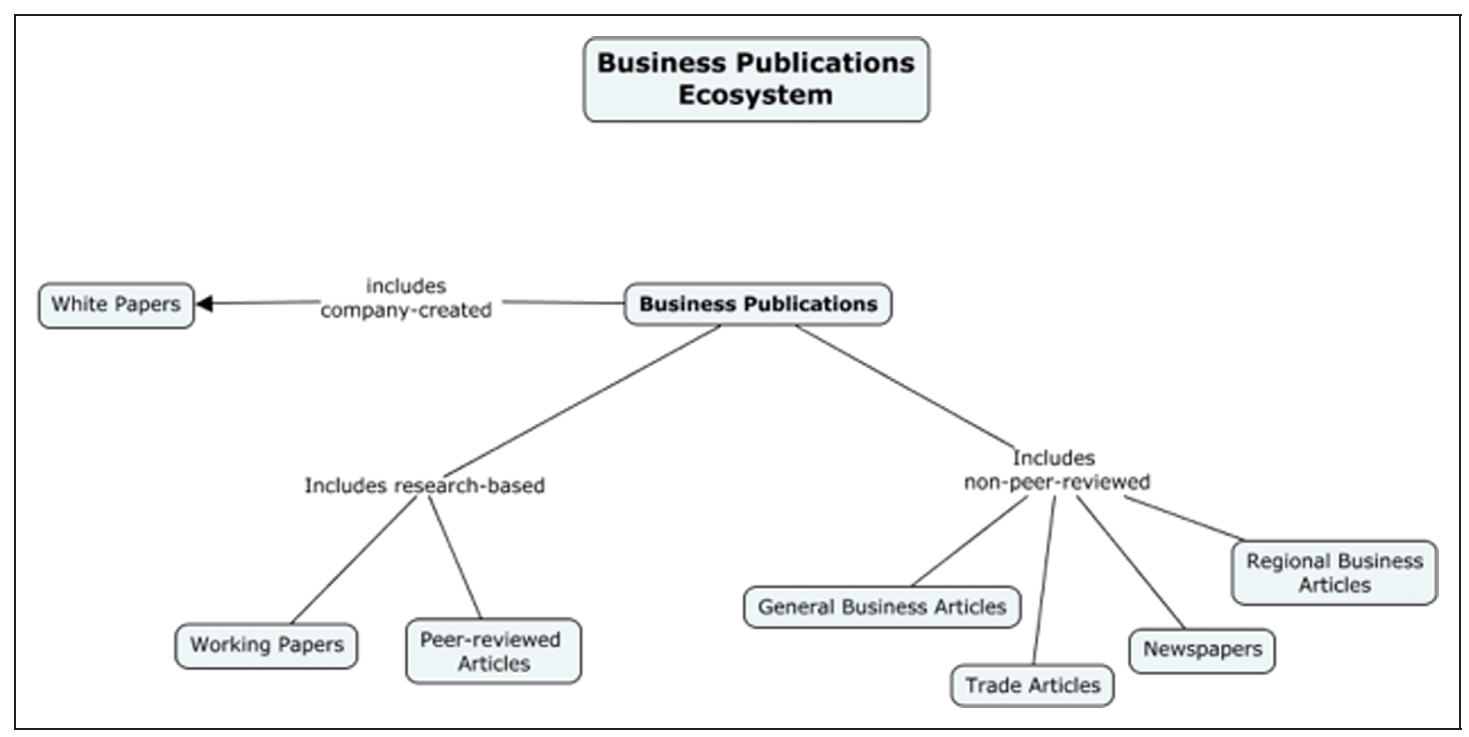




\section{Additional ecosystems}

Adding additional ecosystems of business information creates a richer and more complicated model. Demographics and consumer buying habits provide information from economic census data, retail sales data, and consumer surveys.

International business data add a layer of complexity that includes country economic data, intergovernmental and nongovernmental agencies, and general economic data. Economics and international business and trade are interconnected in their information flow.

Accounting and tax-related information is a connected component of both economics and company activities. These laws and regulations affect economics at both a macro and micro level while they in turn cause companies to track and manage their internal financial information by specific rules. Each of these ecosystems has their own selection of databases and resources to be searched and understood within the context of business information literacy.

\section{Unified theory of business information ecosystems: Business information triangle}

The business information triangle is a model for understanding the origin of information in broad categories as well as the flow of information as it permeates out into the information space. For students, information professionals, and executives having a more holistic understanding of the business information ecosystem can be beneficial for being more informed and for improved decision-making. The underlying concept of the triangle is not original. Natt (2013) displays in his article a Venn diagram of business literature, market research, and financial information to highlight the interconnections between these information groupings.

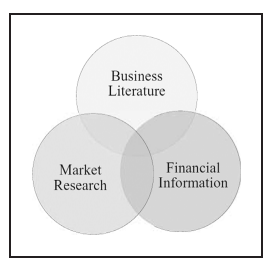

The basic idea itself seems to go back through numerous other articles whenever business information is discussed. The framework presented here, in two iterations, displays how these information ecosystems connect, creating a unified visual representation of business information.

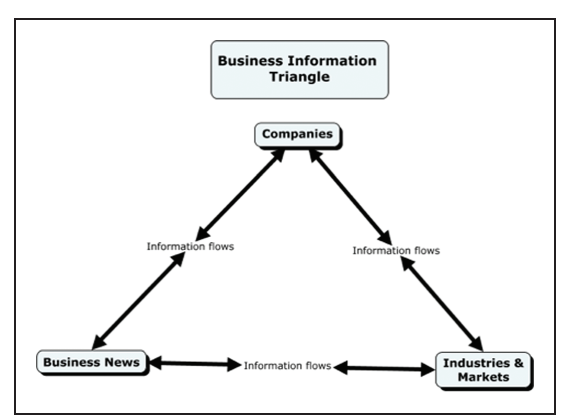

The basic triangle focuses on the three core areas of business information: companies, industries, and business publications. Most business problems connect to this triangle at one of the points which then leads the researcher toward the other two points. Business information is connected and flows around the triangle. Understanding the sources of information within each ecosystem and how they connect to each other increases the researcher's ability to make a more informed business decision.

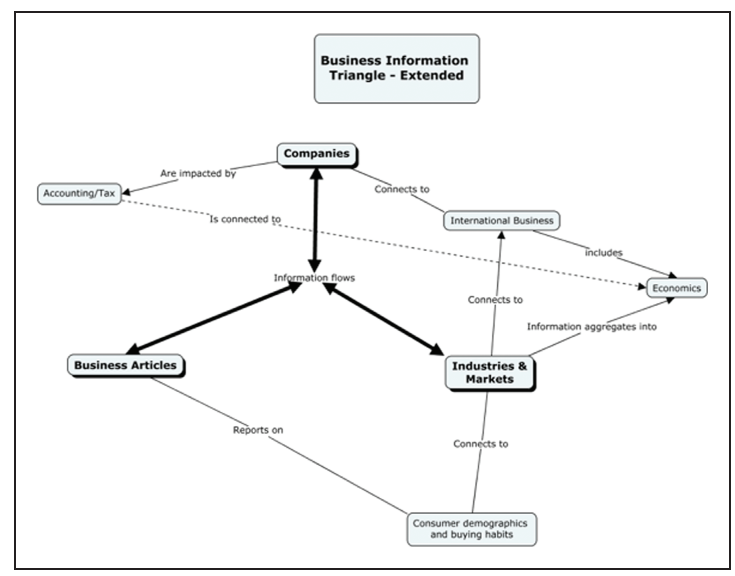


The enhanced version adds additional layers of complexity by connecting the additional ecosystems of business information to the core triangle. Additional ecosystems can be identified and added to create an even richer unified map of business information. The more inclusive ecosystem map visually displays the additional complexity of business information.

\section{Conclusion}

The unified theory of business information, consisting of the more detailed topical ecosystems, can be used to teach students, researchers, and information professionals about the depth and breadth of business information in a conceptual context. The visual display creates a clearer picture of the core elements that can allow for better instruction regarding the business information ecosystems. It can then be used to map specific resources and databases to visually display the content within to create a functional context for wayfinding the right business information resource for a given information need. These can be static or interactive maps for facilitating resource identification and use. This technique could be used for mapping, in even more detail, focused company/ industry ecosystems for research and applied situations. Further research and development into concept mapping both the underlying structure of business information along with the specific resources available will be beneficial to a further understanding of the multitude of business information ecosystems and their relationship to each other.

\section{Declaration of Conflicting Interests}

The author(s) declared no potential conflicts of interest with respect to the research, authorship, and/or publication of this article.

\section{Funding}

The author(s) received no financial support for the research, authorship, and/or publication of this article.

\section{References}

Abels EG, Klein DP (2008) Business Information: Needs and Strategies. Bingley, UK: Academic Press - Emerald.

Cunningham NA (2003) Information competency skills for business students. BRASS Business Reference in Academic Libraries Committee 1(1). Available at: http:/www.ala.org/rusa/sections/ brass/brasspubs/academicbrass/acadarchives/volume1 number1/ academicbrassv1 (accessed 20 March 2017).

Curl S (2001) Subramanyam revisited: creating a new model for information literacy instruction. College and Research Libraries 62(5): 455-464.

Donaldson CA (2004) Information literacy and the McKinsey model: the McKinsey strategic problem-solving model adapted to teach information literacy to graduate business students. Library Philosophy and Practice 6(2).

Fleisher CS, Bensoussan BE (2007) Business and Competitive Analysis. New Jersey: Pearson Education, 2007.

Gil E, Reyes A (2012) International Business Research: Strategies and Resources. Plymouth, UK: Scarecrow Press.

Heckman L (2011) How To Find Business Information: A Guide for Businesspeople, Investors, and Researchers. Santa Barbara, CA: Praeger.

Karp RS (2002) The Basic Business Library. Westport, CT: Greenwood Publishing Co.

Kelly E, Armstrong M, Bruun-Jensen J, et al. (2015) Business Ecosystems Come of Age. Westlake, TX: Deloitte University Press.

Mayer E (2013) 50 Competitive Intelligence Analysis Techniques. Competia. Available at: http://competia.com/50-competitiveintelligence-analysis-techniques (accessed 16 March 2017).

Moss R (2004) Strauss's Handbook of Business Information: A Guide for Librarians, Students, and Researchers. Westport, CT: Libraries Unlimited.

Natt A (2013) What is business information literacy and can the corporate librarian contribute anything to the discourse. Journal of Business and Finance Librarianship 18(2): 146-174.

Porter ME (1985) Competitive Advantage: Creating and Sustaining Superior Performance. New York: The Free Press.

Porter ME (1991) Michael E. Porter on Competition and Strategy. Boston, MA: Harvard Business School Publishing.

Rouse M (2005) Unified field theory or theory of everything. WhatIs.com. Available at: http://whatis.techtarget.com/defini tion/unified-field-theory-or-Theory-of-Everything-TOE (accessed 16 March 2017).

Spencer N (2009) Business information resources: landscape and feasibility study. Available at: http://www.jisc.ac.uk/media/doc uments/programmes/bce/stream4resfinalreport.pdf (accessed 20 March 2017).

Subramanyam K (1981) Scientific and Technical Information Resources. New York: Marcel Dekker, 1981.

Tegarden DP (1999) Business information visualization. Communications of the Association for Information Systems 1(4).

\section{Author biography}

Hal P Kirkwood is an associate professor of library science and business information specialist in the Roland G. Parrish Library of Management \& Economics at Purdue University, West Lafayette, Indiana, USA. He is a past director on the Board of the Special Libraries Association. He has presented at numerous conferences including SLA, Computers in Libraries, and International Internet Librarian. His research interests focus on business information literacy, concept mapping, and competitive intelligence. 